\title{
The first case of multiple pulmonary granulomas with amyloid deposition in a dental technician; a rare manifestation as an occupational lung disease
}

Taizou Hirano ${ }^{1,2}$, Tadahisa Numakura ${ }^{1,2^{*}}$, Hiroshi Moriyama ${ }^{3}$, Ryoko Saito ${ }^{4}$, Yutaka Shishikura ${ }^{1,2}$, Jun Shiihara ${ }^{2,5}$, Hisatoshi Sugiura ${ }^{1}$ and Masakazu Ichinose ${ }^{1}$

\begin{abstract}
Background: Occupational lung diseases, such as pneumoconiosis, are one of the health problems of dental workers that have been receiving increasing interest. Pulmonary amyloidosis is a heterogenous group of diseases, and can be classified into primary (idiopathic) and secondary (associated with various inflammatory diseases, hereditary, or neoplastic). To date, the development of pulmonary amyloidosis in dental workers has not been reported.

Case presentation: A 58-year-old Japanese female presented with chest discomfort and low-grade fever that has persisted for 2 months. She was a dental technician but did not regularly wear a dust mask in the workplace. Chest $\mathrm{X}$ ray and computed tomography revealed multiple well-defined nodules in both lungs and fluorodeoxyglucose (FDG)-positron emission tomography revealed abnormal FDG uptake in the same lesions with a maximal standardized uptake value (SUV [max]) of 5.6. We next performed thoracoscopic partial resection of the lesions in the right upper and middle lobes. The histological examination of the specimens revealed granuloma formation with foreign body-type giant cells and amyloid deposition that was confirmed by Congo red staining and direct fast scarlet (DFS) staining that produce apple-green birefringence under crossed polarized light. Because there were no other causes underlying the pulmonary amyloidosis, we performed electron probe X-ray microanalysis (EPMA) of the specimens and the result showed silica deposition in the lesions. Based on these results, we finally diagnosed the patient with pulmonary granulomas with amyloid deposition caused by chronic silica exposure. Afterward, her symptoms were improved and the disease has not progressed for 2 years since proper measures against additional occupational exposure were implemented.
\end{abstract}

Conclusions: Our case presented three important clinical insights: First, occupational exposure to silica in a dental workplace could be associated with the development of amyloid deposition in lung. Second, EPMA was useful to reveal the etiology of amyloid deposition in the lungs. Last, proper protection against silica is important to prevent further progression of the disease. In conclusion, our case suggested that occupational exposure to silica should be considered when amyloid deposition of unknown etiology is found in the lungs of working or retired adults.

Keywords: Dental technician, Amyloid deposition, Pulmonary granulomas, Silica

\footnotetext{
* Correspondence: tnumakura@rm.med.tohoku.ac.jp

${ }^{1}$ Department of Respiratory Medicine, Tohoku University Graduate School of

Medicine, 1-1 Seiryou-machi, Aoba-ku, Sendai 980-8574, Japan

${ }^{2}$ Department of Respiratory Medicine, Hiraka General Hospital, Yokote, Japan

Full list of author information is available at the end of the article
}

(c) The Author(s). 2018 Open Access This article is distributed under the terms of the Creative Commons Attribution 4.0 International License (http://creativecommons.org/licenses/by/4.0/), which permits unrestricted use, distribution, and reproduction in any medium, provided you give appropriate credit to the original author(s) and the source, provide a link to the Creative Commons license, and indicate if changes were made. The Creative Commons Public Domain Dedication waiver (http://creativecommons.org/publicdomain/zero/1.0/) applies to the data made available in this article, unless otherwise stated. 


\section{Background}

Occupational and environmental lung diseases are a broad group of pulmonary disorders caused by the inhalation of harmful dusts, chemicals, or proteins [1] and are one of the health problems among dental workers receiving increasing interest [2, 3]. Working with dental abrasives and polishing materials can result in chronic exposure to various harmful materials such as silica, alloys, and acrylic plastics [2-5]. Pneumoconiosis is a well-known pulmonary disease in dental workers [2-5]. Although various types of pneumoconioses have been reported [2-6], to our knowledge, the development of pulmonary amyloidosis has not been reported. Here, we describe the first reported case of a dental worker who developed multiple granulomas with amyloid deposition in the lung, which may have resulted from long-term exposure to silica in the workplace.

\section{Case presentation}

A 58-year-old Japanese woman presented with chest discomfort and low-grade fever that had persisted for 2 months. She was a dental technician but did not regularly wear a dust mask in the workplace. She previously had a smoking history of 2 pack/year and no medical history. On admission, her body temperature was $37^{\circ} \mathrm{C}$. Physical examination results were almost normal. The laboratory examinations were also normal including blood smear differentials, C-reactive protein, serological tests for autoimmune disorders and malignant and hematological disorders, and serological tests for infectious diseases (Table 1). Chest $\mathrm{X}$ ray and computed tomography revealed multiple well-defined nodules in both lungs (Fig. 1a and b) and fluorodeoxyglucose (FDG)-positron emission tomography revealed abnormal FDG uptake in the same lesions with a maximal standardized uptake value (SUV $[\max ]$ ) of 5.6 (Fig. 1c). Then, we performed thoracoscopic partial resection of the lesions in the right upper and middle lobes (Fig. 2a). Histological examination of the specimens revealed foreign body-type giant cells and mild and focal chronic inflammatory changes with the infiltration of lymphocytes and plasma cells together with eosin-positive deposits (Fig. 2b). The deposits were direct fast scarlet (DFS) staining positive and produced an apple-green birefringence under crossed polarized light (Fig. 2d and e). Congo-red staining was also positive (Fig. 2f). Based on these results, we concluded that the substance in the lesion was compatible with amyloid. Although we diagnosed the patient with pulmonary amyloidosis, there was no obvious underlying causes that could typically cause pulmonary amyloidosis, including rheumatoid arthritis, primary Sjögren's syndrome or multiple myeloma. We also excluded plasma cell neoplasm and multicentric Castleman's disease because there was no infiltration of atypical plasma cells nor formation of multicentric lymphoid follicles in the lesions. Consequently, we focused on her occupational history and performed electron probe X-ray microanalysis (EPMA) of the specimens to evaluate the cause of pulmonary amyloidosis. EPMA of the specimens revealed the deposition of silica throughout the granulomatous lesions as well as among giant cells (Fig. $2 \mathrm{~g}$ and $\mathrm{h}$ ). From these results, we finally diagnosed the patient with multiple lung granulomas with amyloid deposition caused by chronic silica exposure. Afterward, her symptoms improved and the disease has not progressed for 2 years since proper measures against additional occupational exposure were implemented.

\section{Discussion and conclusions}

Occupational lung diseases are caused by exposure to various toxic materials in the workplace environment. The inhaled dust particles are deposited around terminal bronchiole to their neighborhood alveoli due to their size and air speed causing lung injury and inflammation by the released oxidants, enzymes, growth factors, and other inflammatory cytokines [1]. Dental workers are exposed to various types of dusts such as silica, aluminum oxide and heavy metals when polishing and grinding prosthetics and during casting operations. Such exposure can increase the risk of occupational lung disease [2-6]. Silica, which was identified in our case, is associated with a variety of occupational lung diseases including silicosis, tuberculosis, obstructive lung disease, and lung cancer. Thus, Japan Society for Occupational Health recommends that the maximum allowable concentration (MAC) of silica is less than $0.03 \mathrm{mg} / \mathrm{m}^{3}$ [7]. However, the concentration of silica in the workplace environment of dental workers sometimes exceeds the MAC. For example, one study showed that the concentration of silica in the air of the work environment of dental workers to be as high as $0.051 \mathrm{mg} / \mathrm{m}^{3}$ [6]. The most common occupational lung disease caused by silica exposure is pneumoconiosis $[8,9]$. Most cases develop without symptoms, whereas cough, shortness of breath and fever may develop in severe cases $[8,9]$. Although various types of pneumoconioses have been reported, the development of pulmonary amyloidosis in dental workers has not been reported according to our PubMed search.

Amyloidosis is a heterogeneous group of diseases characterized by the deposition of Congo red and DFS positive amyloid fibrils in the extracellular matrix of organs such as lung [10, 11]. Radiological findings of pulmonary amyloidosis can be typically classified into several clinical types, such as showing a diffuse alveolar septal pattern, single or multiple pulmonary nodules and tracheobronchial amyloidosis [10,11]. The diagnosis of pulmonary amyloidosis sometimes requires surgical lung biopsy to confirm the histopathological findings with Congo red staining, which produces an apple-green birefringence 
Table 1 Results of laboratory examinations on admission

Blood count
WBC
Neut
Eos
Bas
Mo
Ly
RBC
Hb
Plt

Arterial blood gas (room air)

$\mathrm{pH}$
$\mathrm{PaO}_{2}$
$\mathrm{PaCO}_{2}$
$\mathrm{HCO}_{3}^{-}$

$\mathrm{BE}$

Blood chemistry

TP

Alb

T-bil

AST

ALT

$\mathrm{LDH}$

ALP

YGTP

BUN

Cre

$\mathrm{Na}$

K

$\mathrm{Cl}$

$\mathrm{Ca}$

Serum

CRP

$\lg G$

$\lg A$

$\lg M$

$\operatorname{lgG} 4$

CEA

CA19-9

ANA

Anti CCP antibody

anti SS-Aantibody

Anti SS-B antibody

Serum amyloid $A$

$s-I L-2 R$

7.427
Table 1 Results of laboratory examinations on admission (Continued)

\begin{tabular}{ll}
\hline$\beta$-D glucan & $<5.0 \mathrm{pg} / \mathrm{ml}$ \\
Cryptococcus antigen & negative \\
Aspergillus antigen & negative \\
Candida antigen & negative \\
T-SPOT & negative \\
Serum protein electrophoresis & \\
M protein & negative \\
Urine protein electrophoresis & \\
Bence-Jones protein & negative \\
\hline
\end{tabular}

Neut neutrophil, UA uric acid, CRP C-reactive protein, CEA carcinoembryonic antigen, CA19-9 carbohydrate antigen 19-9, CCP cyclic citrullinated peptide, $s-I L-2 R$ soluble interluekin 2 receptor

94.5 Torr

36.8 Torr

$23.7 \mathrm{mEq} / \mathrm{l}$

$-0.3 \mathrm{mEq} / \mathrm{l}$

under crossed polarized light. Pulmonary amyloidosis can be classified into primary (idiopathic) and secondary (associated with various inflammatory diseases, hereditary, or neoplastic) $[9,10]$. In the present case, there was no obvious cause underlying the pulmonary amyloidosis. Therefore, taking into account the patient's occupation and the histological findings of foreign body-type giant cell granulomas in the lung, we performed EPMA for further evaluation.

EPMA with a wavelength dispersive spectrometer (WDS) is a method of mineralogical analysis that can qualitatively and semi-quantitatively analyze the chemical composition of solid materials found in human tissue histology [12] Takada et al. analyzed 162 cases of suspected occupational and environmental lung diseases by EPMA-WDS, and concluded that EMPA-WDS was useful to confirm the causes of various occupational and environmental lung diseases [12]. Although it is unknown whether the inhaled silica was a direct cause of the pulmonary amyloidosis, our histological as well as EPMA findings (Fig. 2) suggest that the chronic exposure to silica in a dental office could be associated with chronic inflammation, resulting in the development of amyloid deposition in the lung. Furthermore, a recent scientific report demonstrating that exposure to silica could increase the production of Congo-philic amyloid deposition in C. elegans also supported our findings [13]. Because there is no proven specific treatment for such patients, clarifying the occupational cause is key to prevention with effective occupational safety measures, such as good ventilation in the laboratory and personal protective devices, to avoid further progression of the disease.

In summary, we report the first case of a dental worker who developed multiple granulomas with amyloid deposition in the lungs likely caused by silica exposure in the workplace. Our case presented three important clinical insights: First, chronic exposure to silica in dental workplace could be associated with the development of amyloid deposition in lung. Second, EPMA was useful 

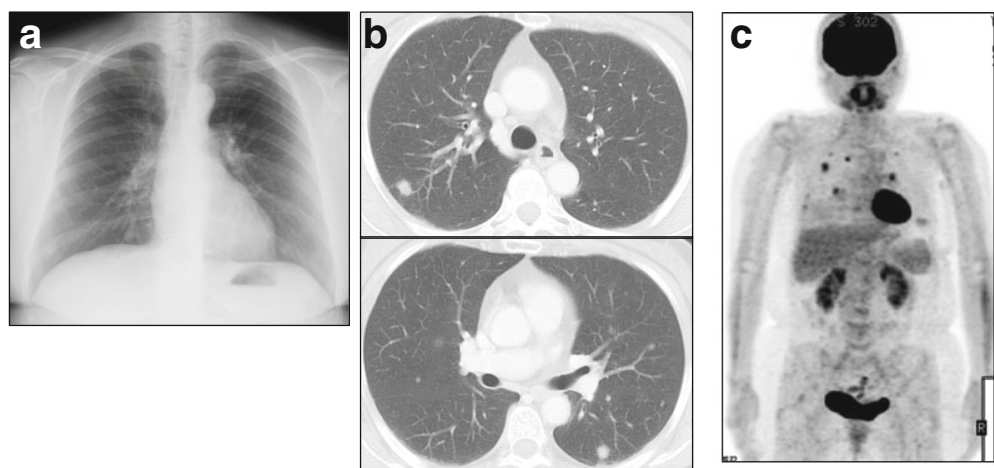

Fig. $\mathbf{1}$ a, b Chest $X$ ray (a) and chest computed tomography on admission (b) revealed multiple well-defined nodules in both lungs. $\mathbf{c}$ Fluorodeoxyglucose (FDG)-positron emission tomography revealed abnormal FDG uptake in the same lesions with a maximal standardized uptake value (SUV [max]) of 5.6

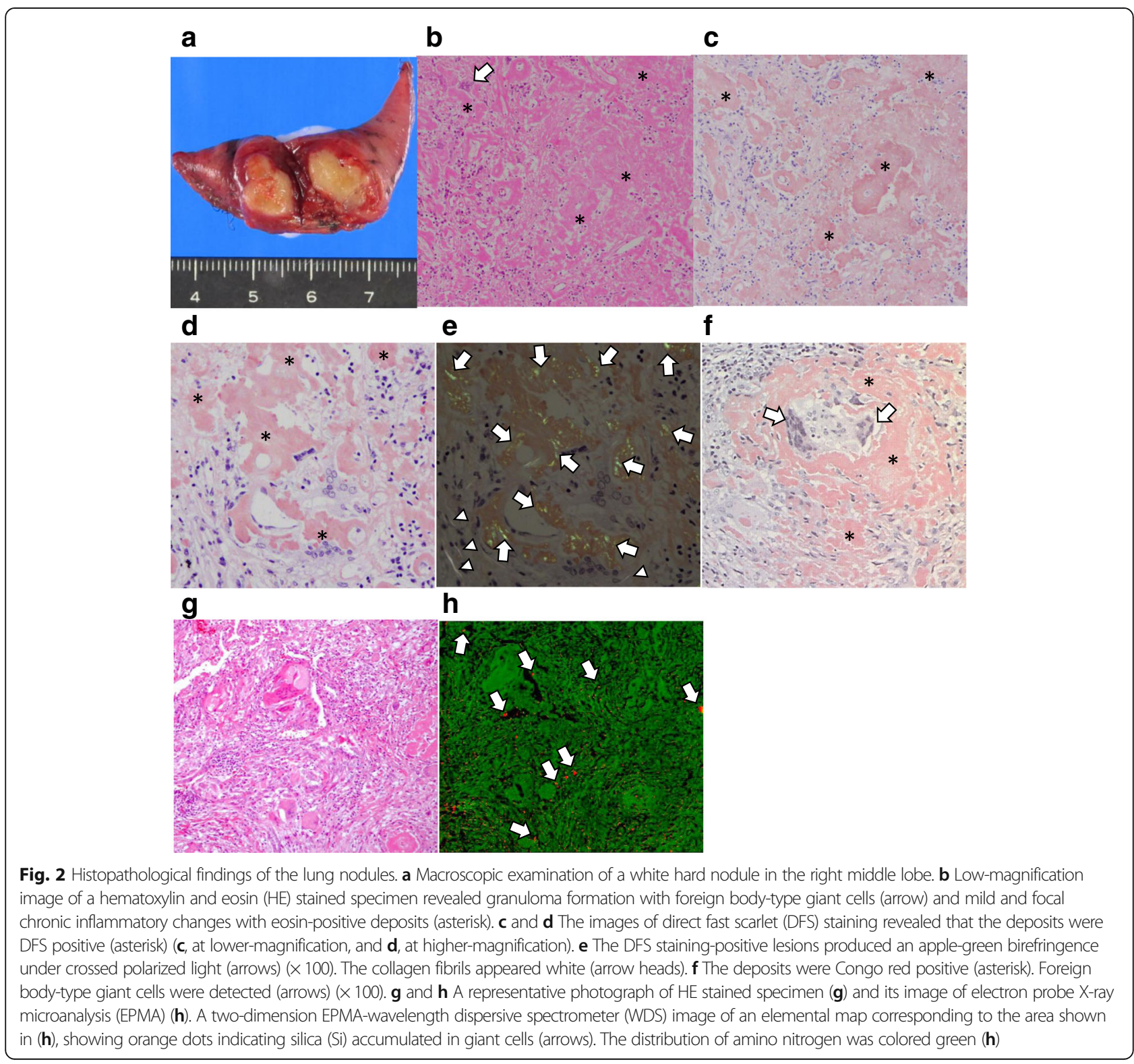


to reveal the unknown etiology of amyloid deposition in lung. Last, proper protection against silica is important to prevent further progression of the disease. In conclusion, occupational exposure to silica should be considered when amyloid deposition of unknown etiology is found in the lungs of working or retired adults.

\section{Abbreviations}

EPMA: Electron probe X-ray microanalysis; FDG-PET: Fluorodeoxyglucose (FDG)-positron emission tomography (PET); HE: Hematoxylin and eosin; MAC: Maximum allowable concentrations; SUV [max]: Maximal standardized uptake value; WDS: Wavelength dispersive spectrometer

\section{Acknowledgements}

We very much appreciate Mr. Brent K. Bell for critical reading of the manuscript.

\section{Funding}

This work was funded by the Japan Society for the Promotion of Science (grant number; 17H04180, 16 K15453).

\section{Availability of data and materials}

All the data supporting our findings is contained within the manuscript.

\section{Authors' contributions}

TH, TN, YS, JS, HS and MI performed clinical, functional and laboratory assessments. HM performed the EMS analysis. RS performed and interpreted the histopathological examinations. All authors significantly contributed to the data interpretation and manuscript preparation. All authors read and approved the final manuscript.

Ethics approval and consent to participate

Ethical approval to report this case was not required.

\section{Consent for publication}

Written informed consent was obtained from the patient for the publication of this case report and all accompanying images.

\section{Competing interests}

The authors declare that they have no competing interests.

\section{Publisher's Note}

Springer Nature remains neutral with regard to jurisdictional claims in published maps and institutional affiliations.

\section{Author details}

${ }^{1}$ Department of Respiratory Medicine, Tohoku University Graduate School of Medicine, 1-1 Seiryou-machi, Aoba-ku, Sendai 980-8574, Japan. ²Department of Respiratory Medicine, Hiraka General Hospital, Yokote, Japan. ${ }^{3}$ Department of Respiratory Medicine, Nishi-Niigata Chuo National Hospital, Niigata, Japan. ${ }^{4}$ Department of Anatomic Pathology, Tohoku University Graduate School of Medicine, Sendai, Japan. ${ }^{5}$ Department of Respiratory Medicine, Saitama

Medical Center Jichi Medical University, Saitama, Japan.

Received: 19 September 2017 Accepted: 16 May 2018

Published online: 22 May 2018

\section{References}

1. William SB. Occupational respiratory diseases. New Engl J Med. 2000;342: 406-13.

2. Malhotra P, Sarkar PK, Sriram PS. An 84-year-old man with acute dyspnea and chronic radiographic findings. Chest. 2013;144:1076-9.

3. Kuehn B. Dentists at risk of lung disease? JAMA. 2018;319(16):1650. https:// doi.org/10.1001/jama.2018.4585.

4. Ardekani A, Ayatollahi J, Ayatollahi F, Bahrololoomi R, Ayatollahi J, Ayatollahi A, et al. Occupational hazards to dental staff. Dent Res J (Isfahan). 2012;9:2-7.

5. Orriol R, Ferrer J, Tura JM, Xaus C, Coloma R. Sicca syndrome and silicoproteinosis in a dental technician. Eur Respir J. 1997;10:731-4.

6. Torbica N, Krstev S. World at work: dental laboratory technicians. Occup Envirion Med. 2006;63:145-8.
7. The Japan Society for Occupational Health. Recommendation of occupational health limits (2013-2014). J Occup Health. 2013;55:422-41.

8. Greenberg MI, Waksman J, Curtis J. Silicosis: a review. Dis Mon. 2007;53:394-416.

9. $\quad$ Leung CC, Yu IT, Chen W. Silicosis. Lancet. 2012;26:2008-18.

10. Khoor A, Colby TV. Amyloidosis of the lung. Arch Pathol Lab Med. 2017;141: 247-54.

11. Gillmore JD, Hawkins PN. Amyloidosis and the respiratory tract. Thorax. 1999:54:444-51.

12. Takada T, Moriyama H, Suzuki E. Elemental analysis of occupational and environmental lung diseases by electron probe microanalyzer with wavelength dispersive spectrometer. Respirlnvestig. 2014;52:5-13.

13. Scharf A, Gührs K-H, von Mikecz A. Anti-amyloid compounds protect from silica nanoparticle-induced neurotoxicity in the nematode C. elegans. Nanotoxicology. 2016;10:426-35.

\section{Ready to submit your research? Choose BMC and benefit from:}

- fast, convenient online submission

- thorough peer review by experienced researchers in your field

- rapid publication on acceptance

- support for research data, including large and complex data types

- gold Open Access which fosters wider collaboration and increased citations

- maximum visibility for your research: over $100 \mathrm{M}$ website views per year

At BMC, research is always in progress.

Learn more biomedcentral.com/submissions 